\title{
Simulation of wind power with front-end converter into interconnected grid system
}

\author{
Sharad W. Mohod'; Mohan V. Aware ${ }^{2}$ \\ ${ }^{1}$ Meghe Institute of Technology \& Research, Badnera-(INDLA); \\ ${ }^{2}$ Visvesvaraya National Institute of Technology Nagpur-(INDIA) \\ sharadmobod@rediffmail.com;.nva_win@yahoo.com
}

Received May 2009

Accepted July 2009

\begin{abstract}
In the growing electricity supply industry and open access market for electricity worldwide, renewable sources are getting added into the grid system. This affects the grid power quality. To assess the impact on grid due to wind energy integration, the knowledge of electrical characteristic of wind turbine and associated control equipments are required. The paper presents a simulation set-up for wind turbine in MATLAB / SIMULINK, with front end converter and interconnected system. The presented control scheme provides the wind power flow to the grid through a converter. The injected power in the system at the point of common coupling is ensured within the power quality norms.
\end{abstract}

Keywords: power quality, wind generating system

\section{Introduction}

Generation of electricity from wind is the fastest growing energy technology in the world. India is in the $4^{\text {th }}$ rank and has a renewable energy gross potential installed of $7855 \mathrm{MW}$ as on 2006. With increasing wind power production, it is important for grid owners, to predict the grid interaction of wind turbine in advance. Some grid simulation packages like power system simulator are used for power system behavioral studies. Models of new types of generating units, like wind turbine have to comply with the requirement. Considering wind turbine generating system 
operation in electric power system, it is necessary to utilize the steady state model for analysis, related to load flow, short circuit calculation, power quality assessments, etc. The electric utility grid system cannot accept connection of new generation plant without strict condition, due to the real power fluctuation and reactive power generation of wind plants. Therefore the penetration of wind power in grid implies taking care of power quality issues like voltage variation on grid, switching operation of wind turbine (Reid, 1996). Today grid connected wind turbines are equipped with power converter systems. The wind-generation system interconnected with power system as shown in Figure 1.

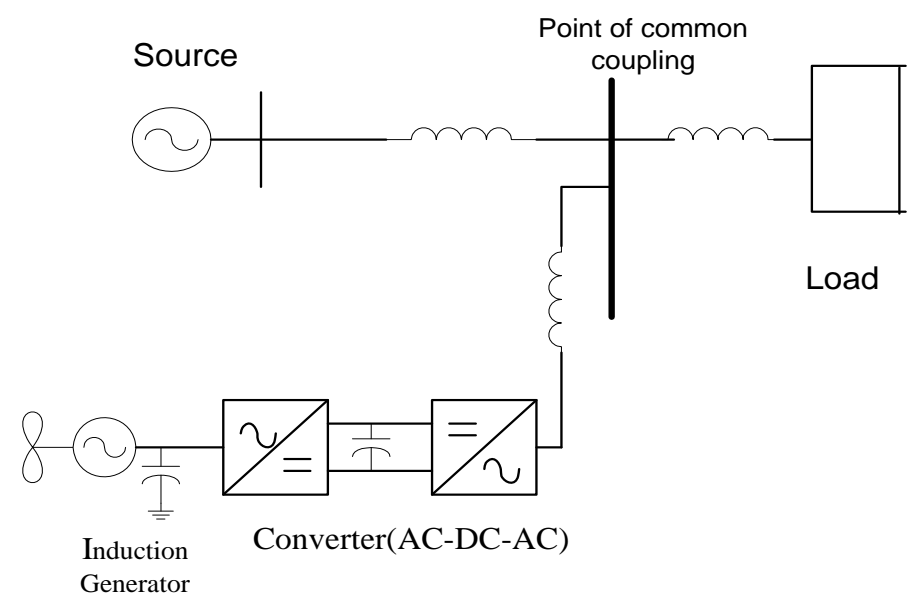

Figure 1. "Wind -Generation system Interconnection with power system".

In modern wind turbine system, power is exchanged with grid through a dedicated power interface so as to improve the power quality norms and it should compensate for harmonics and reactive power in the system. The typical system is simulated for practical condition in power system and simulated results are presented. The proposed control keeps the unity power factor at the point of common coupling (PCC) and allows the system voltage be stable while compensating the reactive and real power demand of the load. The dynamics of the system and control action is simulated with the detail model of wind generator with front end converter system. This simulation is carried out in SIMULINK with power system block set. 


\section{Model of wind turbine}

The static characteristic of wind turbine can be described by the relation between total power in the wind and mechanical power of wind turbine as in Equation 1. It presents a basic model for wind turbine in electric power system.

$$
P_{\text {wind }}=\frac{1}{2} \rho \Pi R^{2} V_{\text {wind }}^{3}
$$

In wind power Equation 1, where $\rho$ - air density $\left(1.225 \mathrm{Kg} / \mathrm{m}^{3}\right), \mathrm{R}$ is rotor radius in meters, $V_{\text {wind }}$ is the wind speed in $\mathrm{mtr}^{3} / \mathrm{sec}$.

It is not possible to extract all kinetic energy of wind, thus it is extracted a fraction of power in wind as given in Equation 2 and it is called power coefficient $\mathrm{Cp}$ of the wind turbine.

$$
P_{\text {mech }}=C_{p} P_{\text {wind }}
$$

$P_{\text {mech }}$ is the mechanical power of wind turbine in $\mathrm{Nm} / \mathrm{s}$. The power coefficient is given as $C_{p}=\frac{16}{27}=0.59$. This coefficient is also known as Betz's limit. This coefficient can be expressed as a function of tip speed ratio- $\lambda$ and pitch angle- $\theta$. The torque $\mathrm{T}_{\max }$ can be conveniently calculated from power $P_{\text {mech }}$ by using turbine rotational speed $\omega_{\text {turbine. }}$

$T_{\text {mech }}=P_{\text {mech }} / \omega_{\text {turbint }}$

Therefore,

$$
\begin{aligned}
& P_{\text {mech }}=f\left(\omega_{\text {turbine }} V_{\text {wind }}\right) \\
& P_{\text {mech }}=\frac{1}{2} \rho \Pi R^{2} V^{3}{ }_{\text {wind }} C_{p}
\end{aligned}
$$

The tip speed ratio $\lambda$ is defined as Equation 6.

$$
\lambda=\omega_{\text {turbine }} R / V_{\text {wind }}
$$


Assuming constant wind speed $V_{\text {wind }}$, the tips speed ratio $\lambda$ will vary proportionally to the rotational speed of wind turbine rotor (Tande, 2002). The highest value of $C_{p}$ is typically obtained for $\lambda$ values in the range of 8 to 9 (when the tip of the blades moves 8 to 9 times faster than incoming wind). On modern wind turbines, it is possible to adjust the pitch angle of the entire blade through servo mechanism (Jorgensen et al., 1997; Charly, 2007). Assuming constant wind speed $\mathrm{V}_{\text {wind, }}$ the tips speed ratio $\lambda$ will vary proportionally to the rotational speed of wind turbine rotor.If $C_{p}-\lambda$ curve is known for specific wind turbine with a turbine rotor radius $\mathrm{R}$, it is easy to construct the curve of $C_{p}$ against rotational speed for any wind speed. The $C_{p^{-}} \lambda$ curve is shown in Figure 2.

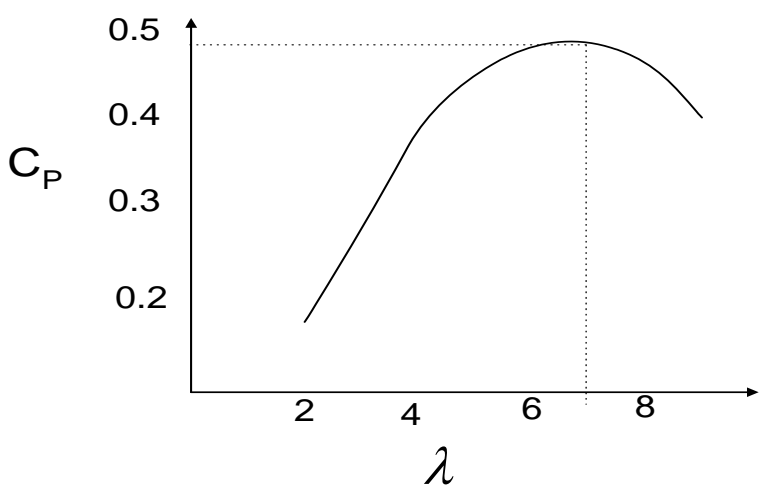

Figure 2. "Cp - $\lambda$ curve".

The wind turbine model is as fallows. The wind turbine model is constructed as shown in Figure 3, once the aerodynamic properties of wind turbine are described.

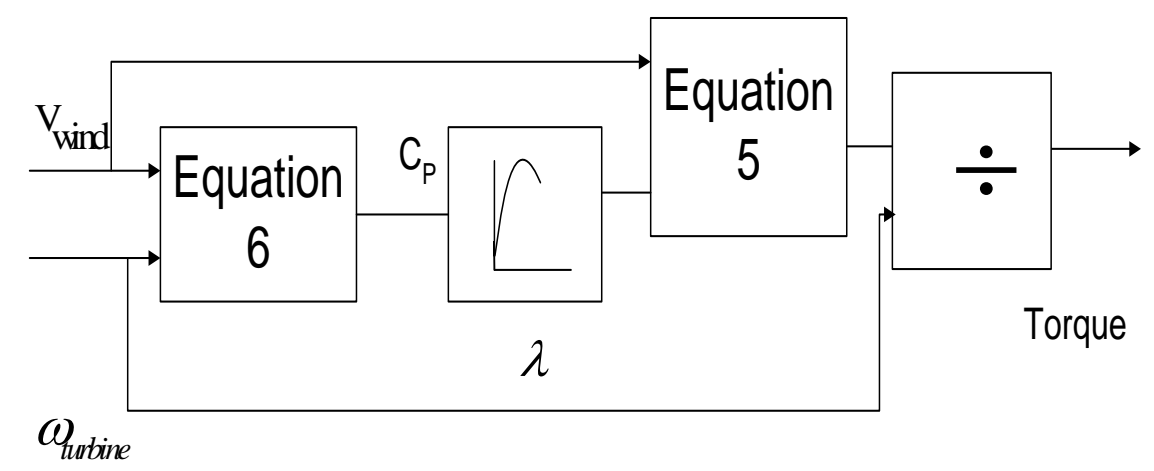

Figure 3. "Model of Wind Turbine". 
Where $V_{\text {wind }}$ and $\omega_{\text {turbine }}$ are input of Equation 6 in the block diagram and $C_{P}$ is calculated and given as input for Equation 5, so as to get output power. This power is divided by $\omega_{\text {turbine }}$ to get output torque.

\section{Control strategy}

The control scheme block diagram for the simulation of power system on grid is shown in Figure 4. The dotted line is the voltage source inverter in current control mode.
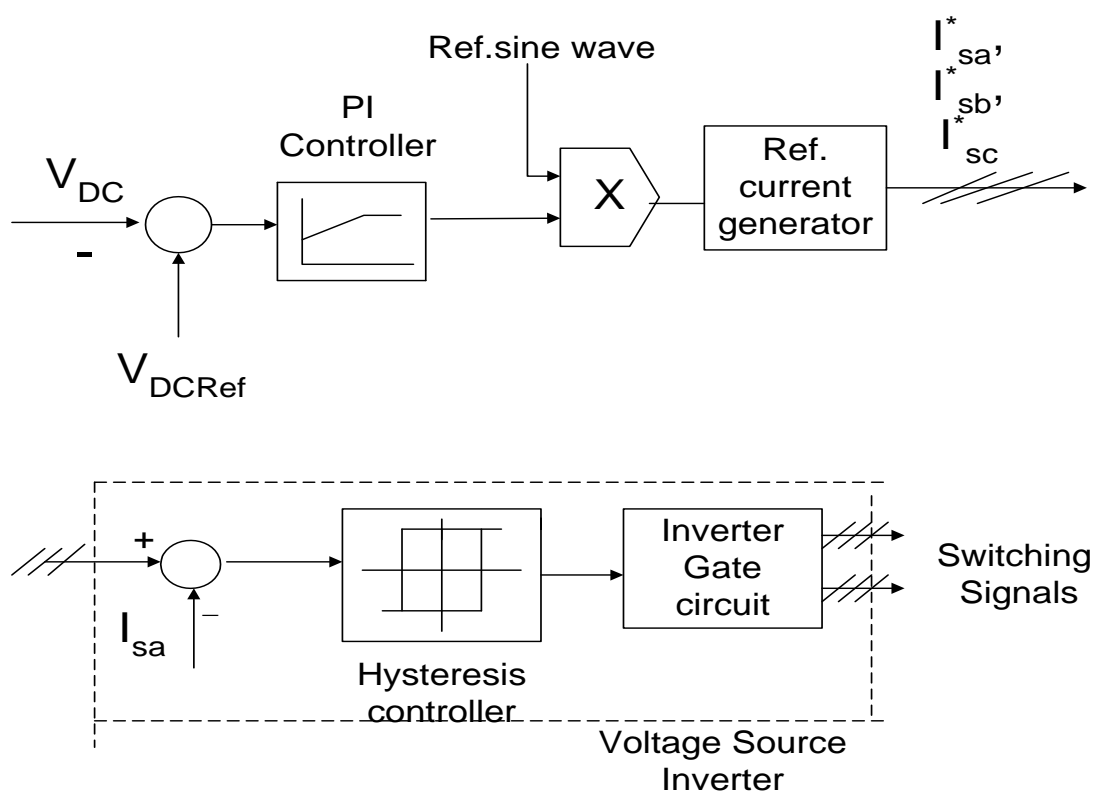

Figure 4. "Control Scheme block diagram".

In the simulation of wind-connected system on grid, the generator is connected to a rectifier. The output of this rectifier is connected to the dc bus. The dc bus voltage at which wind generating system is connected with a set reference values and error is sent into proportional and integral (PI) controller. In PI controller the proportional gain $k_{p}$ will reduce the rise time of error and the integral gain $k_{i}$ will eliminate the effect of steady state error. The output of this controller is given to the multiplier circuit, where a reference sine wave generator multiplies the output of proportional integral PI controller and desired reference current $\mathrm{I}^{*}{ }_{\text {ref. }}$. is obtained. The actual current is detected by current sensor and it is subtracted from desired reference current so that error current is generated and it is sent to hysteresis 
controller to generate the switching pattern (Mohod et al., 2006). Switching signals are obtained by comparing reference currents $i_{s a}^{*}, i_{s b}^{*}, i_{s c}^{*}$ with actual currents $i_{s a}, i_{s b}$ ,$i_{s c}$. Current errors $\Delta i_{a}, \Delta i_{b}, \Delta i_{c}$ are applied to the hysteresis controllers producing the correct signal to switch the power electronics switches ON and OFF. Therefore the reference current for the comparison must be derived from the source voltage. These currents can be expressed as Equation 7.

$i_{s a}=I \sin (\omega t), i_{s b}=I \sin \left(\omega t-120^{\circ}\right), i_{s c}=I \sin \left(\omega t-240^{\circ}\right)$

Where, $I$ is proportional to the magnitude of the filtered source voltage of phase ' $a$ '. This ensures that the source current is controlled to be sinusoidal irrespective of whether the source voltage is unbalanced.

\section{System for simulation}

A grid connected wind turbine generating system is simulated in the SIMULINK using Power System Block set. The variable speed turbine with generator having similar wind characteristics is interfaced with the rectifier unit to get dc bus voltage and ac-dc-ac converter is interfaced to the grid. The system parameters are presented in the Table 1.

\begin{tabular}{|c|c|c|c|}
\hline Source voltage & $\begin{array}{c}415 \mathrm{~V}, \\
50 \mathrm{~Hz}\end{array}$ & $\begin{array}{c}\text { Wind Generator Capacity } \\
\text { (Induction Generator) }\end{array}$ & $\begin{array}{c}175 \mathrm{~kW}, 690 \mathrm{~V}, \\
50 \mathrm{~Hz}\end{array}$ \\
\hline DC Link Voltage & $800 \mathrm{~V} \mathrm{DC}$ & Connected Load & $30 \mathrm{~kW}$ \\
\hline DC Link Capacitor & $5 \mu \mathrm{F}$ & Inverter IGBT, & $40 \mathrm{~kW}$ \\
\hline Boost Inductor & $0.5 \mathrm{mH}$ & Source Inductance & $1 \mathrm{mH}$ \\
\hline
\end{tabular}

Table 1. "Simulation Parameters".

\section{System performance}

The system performance is validated for the grid connected Wind turbine generating system, during the steady state and under dynamic condition. 


\subsection{Steady State Performance}

The result of source current at point of common coupling (PCC) is shown in Figure $5 a$ and non linear load current is shown in Figure $5 \mathrm{~b}$. The injected current from the inverter is shown in Figure $5 \mathrm{c}$.
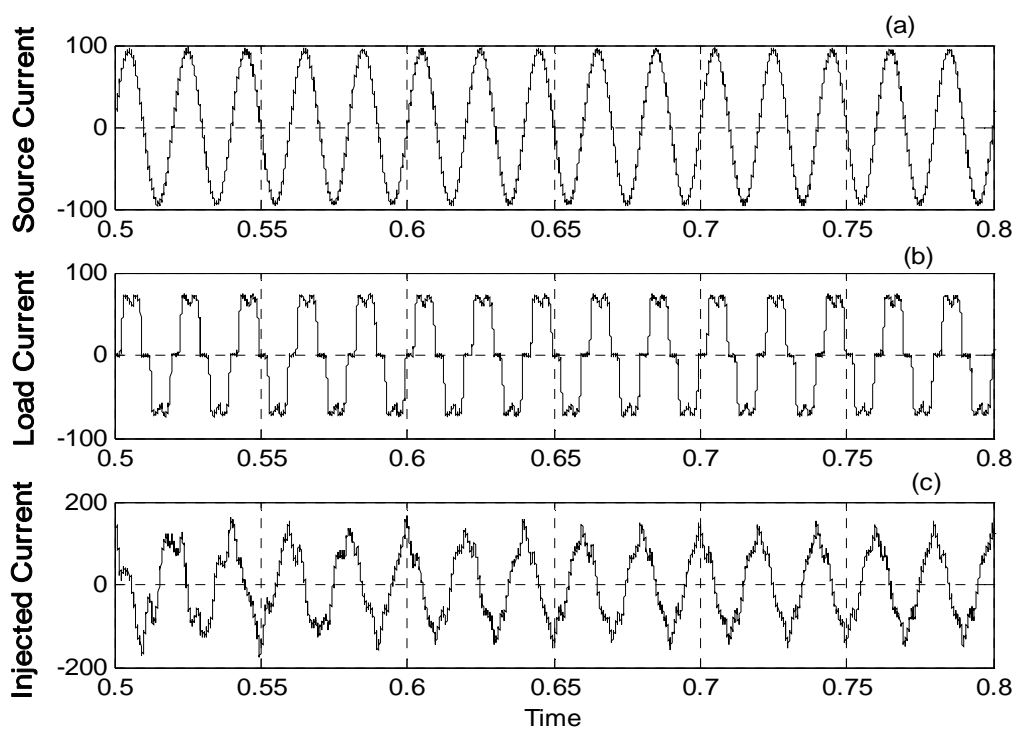

Figure 5a. "Source Current"; 5b. "Load Current"; 5c. "Inverter Current".

The source current is maintained sinusoidal and in phase with source voltage, indicating the unity power factor at PCC and shown in Figure 6.

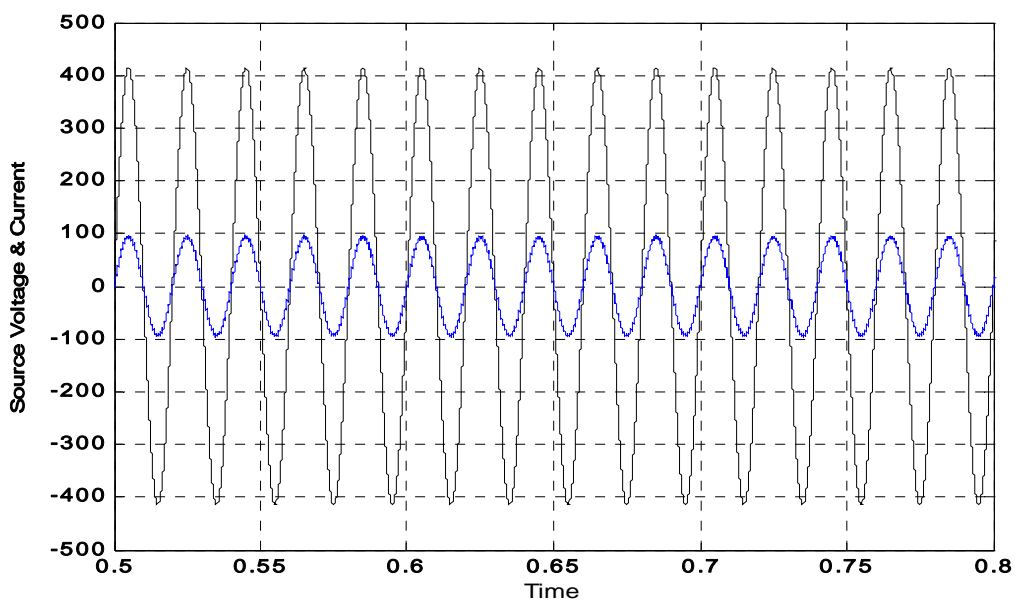

Figure 6. "Source Voltage \& Current at PCC". 
The active power, data 1 in Watt and reactive power flow, data 2 in Watt at the PCC is shown in Figure 7. The reactive power observed is zero, at PCC.

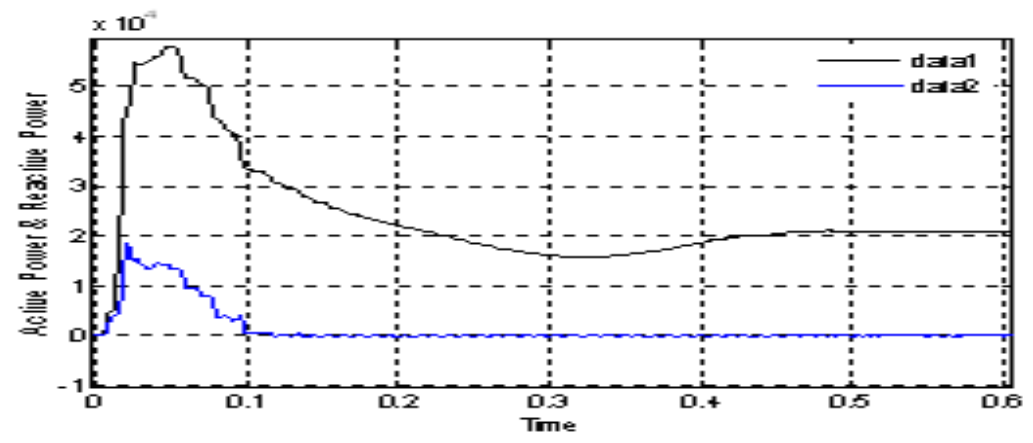

Figure 7. "Active and Reactive power at PCC".

The generated output of wind turbine is rectified and connected to dc link and it is shown in Figure 8.

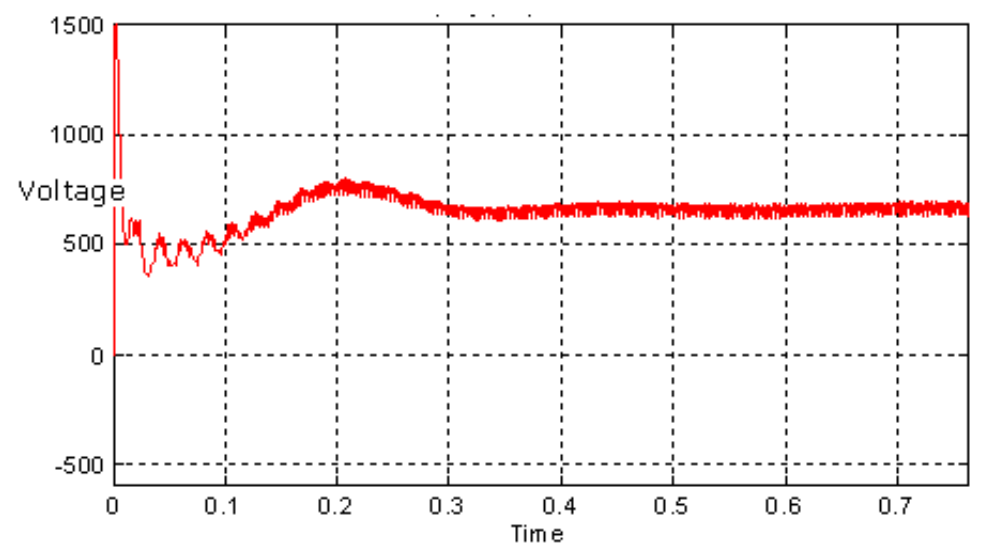

Figure 8. "DC Link Voltage".

\subsection{Performance under dynamic behavior of the system}

The system is supplying the non-linear load and at $0.1 \mathrm{~s}$ breaker is operated and heavy load of $20 \mathrm{KW}$ is suddenly applied causing sudden increase of load current as shown in Figure 9a. Performance of inverter injecting current in the grid is shown in Figure 9b. 


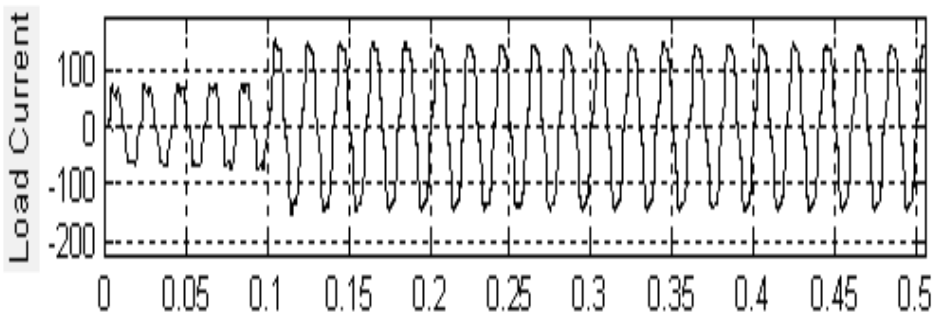

Figure 9a. "Load Current under dynamic behavior".

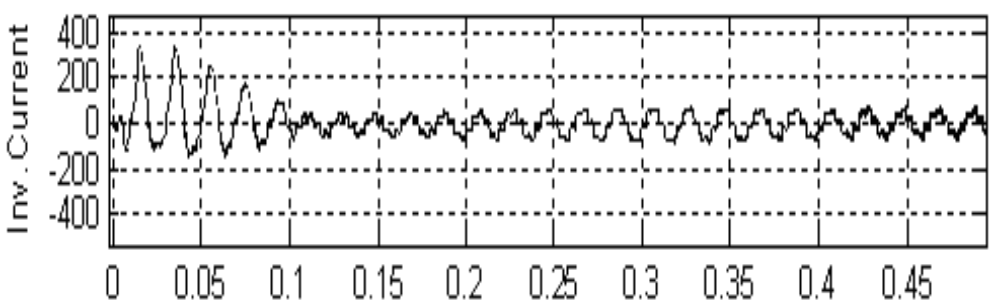

Figure 9b. "Inverter Current under dynamic behavior".

It is observed that at any time the reactive power demand is supplied by inverter. The system makes unity power factor. The system can supply real power and can compensate for reactive power. Thus the simulated system improves grid power quality norm IEC standard 61400-21.

\section{Conclusions}

The Simulated grid connected wind generating system is performing satisfactory for a given load condition. The controller is performing the task of real and reactive power exchange with the power system while maintaining the unity power factor for the supply side. The simulated wind generation systems are connected through the rectifier and inverter and maintain dc bus voltage constant. The exchange of wind power is regulated across the $\mathrm{dc}$ bus and made available under the steady state condition. This also allows the real power flow during the instantaneous demand of the load. The suggested control system is suited for rapid injection or absorption of reactive/real power flow to stabilize the grid system. This satisfies the IEC Standard 61400-21 norms for power quality at the grid. 


\section{References}

Chen, Z., \& Sprioner, E. (2001). Voltage Source Inverters for High Power, Variable Voltage DC Power Supply'. IEEE Proceeding Generation, Transmission and Distribution, 148(5), 419-447.

Ekanayake, J. B., \& Holdsworth, L. (2003). Dynamic Modeling of Doubly fed Induction Generator Wind Turbines'. IEEE Transactions on Power System, 18(7), 803-810.

Lou, C., Banakar, H., \& Shen, B. (2007). Strategies to smooth Wind Power Fluctuations of Wind Turbine Generator, IEEE Conference on Energy Conversion, $22,341-349$.

Jorgensen, P., \& Tande, J. O. (1997). Power Quality and Grid Connection of Wind Turbines. IEEE Conference Publication, 438.

Kinjo, T., \& Senjyu, T. (2006). Output Leveling of Renewable Energy by Electric Double Layer Capacitor Applied for Energy Storage System. IEEE Transaction on Energy Conversion, 21(1).

Matlab (1995). MATLAB / SIMULINK user guide, Math Works inc. USA .

Matsuzaka, T., \& Tsuchiya, K. (1997). Study on stabilization of a wind generation power fluctuation. T.IEE Jpn., 117-B(5) $625-633$.

Mohod, S. W., \& Aware, M. V. (2006). Grid Power Quality with Variable Speed Wind Energy Conversion. Presented at the IEEE International Conference on Power Electronic Drives and System (PEDES) Delhi.

Mohod, S. W., \& Aware, M. V. (2007). Modeling and simulation of Grid Connected Wind Turbine Generating System. Presented at the International Conference on Power Systems (ICPS), Central Power Research Institute, Bangalore.

Nanahara, T. (2000). Recent situation of wind power in foreign countries and their impact on electric power system. T.IEE Jpn, 120 - B(3), 321 - 324.

Petru, O., \& Thiringer, T. (2001). Modeling of Wind Turbines for Power system studies, IEEE Transaction on Power System, 19, 1132-1140. 
Reid, W. E.(1996). Power Quality Issues - Standards and Guidelines. IEEE Transactions on Industry, 625-632.

Smith, J. C., \& Milligan, M. R. (2007). Utility Wind Integration and Operating Impact State of Art. IEEE Transaction on Power System, 22(3), 900-910.

Tande, J. O. Q. (2002). Applying power quality characteristic of wind turbine for assessing impact on voltage quality. Wind Energy, 37-52. license contents, please visit http://creativecommons.org/licenses/by-nc/3.0/. 